\title{
METHOD-MIX FOR THE DEVELOPMENT OF INTERCULTURAL USER INTERFACES EXEMPLIFIED
}

\author{
Rüdiger Heimgärtner \\ Intercultural User Interface Consulting (IUIC), R\&D HMI \\ Lindenstraße 9, 93152 Undorf, Germany
}

\begin{abstract}
In this paper, a method-mix for intercultural user interface design (IUID) is explained and exemplified by an application example to elucidate why and how cultural aspects play a role in UI design and usability/UX engineering. The readers are sensitized to the challenges of intercultural usability/UX engineering and intercultural UI design and will be equipped with methodological knowledge relevant to the derivation of recommendations for user interface design in their desired cultural contexts.
\end{abstract}

\section{KEYWORDS}

Culture, Human Factors, UX, Intercultural User Interface Design, Method Mix, HMI Dimensions

\section{INTRODUCTION AND RELATED WORK}

Intercultural user interface design (IUID) is a prerequisite for improving the intercultural usability of software, which in turn is a prerequisite for global sales opportunities. Using methods of intercultural usability engineering, further design guidelines can be iteratively derived from the results of the tests and the feedback of potential users from all over the world for intercultural user interface design. Based on feedback from tutorials and workshops on IUID (M\&C, Interact, IHCI, SouthCHI, ICCHP, HCII) and the revised summary of the state of research on IUID in (Rüdiger Heimgärtner, 2013a), the author has reviewed the synopsis of well documented IUID methods in academic literature to construct a corresponding method-mix for IUID. This method-mix for the development of intercultural user interfaces will be presented and exemplified by an application example in this paper.

The internal model of the user about the system is shaped by the culture of the user, his expectations about the characteristics of the system and his interaction experience with the system. Differences between cultures can be found by analyzing critical interaction situations between people (Thomas, Kinast, \& Schroll-Machl, 2010). (Honold, 2000) made this method available for cultural differences in Human-Machine Interaction (HMI). Consequentially, critical interaction situations that arise due to problematic user interfaces or are based on the given system functionality must be analyzed. For example, (Vöhringer-Kuhnt, 2002) found that Hofstede's cultural dimension of "Individualism Index" (cf. (Hofstede, Hofstede, \& Minkov, 2010) is related to user satisfaction and usability of the product and has a significant influence on intercultural usability. (Röse, 2002) proposed the "Method for Culture-Oriented Design" (MCD), which integrates cultural differences into existing concepts of HMI design. Relevant cultural variables for intercultural HMI design must be determined analytically based on literature and requirement studies. Their values represent culture-dependent variations that occur at all levels of HMI localization (interface, functionality and interaction) and can be used for IUID. Similarly, (Shen, Woolley, \& Prior, 2006) focus on culture-oriented design. Further methods are applying user interface characteristics by (Marcus, 2006) or cultural markers by (Badre \& Barber, 1998). More recent approaches e.g. by (Castro Salgado, Leitão, \& Souza, 2013) are based on semiotic theory, such as (Pereira, Baranauskas, \& Liu, 2015) or (Zheng, Rau, Yueh, Chen, \& Huang, 2018). One of the most promising methods to preserve cultural differences in HMI is the observation and analysis of user interaction with the system (cf. (Rüdiger Heimgärtner, 2012)). The results of these observations in the form of cultural variables and their manifestations serve as a basis for IUID recommendations and guidelines. 


\section{IUID METHOD-MIX}

The IUID method mix (Rüdiger Heimgärtner, 2017) consists of a combined and hybrid use of cultural dimensions, intercultural variables, user interface characteristics, and HMI dimensions within the method of culture-oriented design. These core concepts of the IUID method-mix are introduced briefly.

The characteristics of cultural dimensions influence the user experience and provide orientation for the usability engineering process. Differences between cultures can be found by analyzing critical interaction situations between people (cf. (Thomas et al., 2010)) expressed by cultural dimensions (cf. (Hofstede et al., 2010)) that serve to describe and compare cultural systems (cf. (Hall \& Hall, 2009)). Using the "Method for Culture-Oriented Design" (Röse, 2002), relevant cultural variables for intercultural HMI design can be determined analytically based on literature research and requirement studies. Their values represent culture-dependent variations that occur at all levels of HMI localization (surface, functionality and interaction) describing the differences in HMI design with respect to the preferences of users from different cultures. "Visible" intercultural variables are immediately perceptible at any certain time (font, color, window size, navigation, etc.). In contrast, "invisible" (or "hidden") intercultural variables are only recognizable over a certain period (interaction speed, information display duration, dialogue display frequency, use of the navigation bar, etc.). The user interface characteristics "Metaphor", "Mental Model", "Navigation", "Interaction" and "Presentation" (Marcus, 2006) are linked to five of Hofstede's cultural dimensions (Hofstede et al., 2010) (cf. (Röse, 2002)). User interface characteristics can be used in conjunction with empirical surveys on their characteristics for the corresponding cultural target context to derive recommendations for the development of intercultural user interfaces. HMI dimensions describe the behavior of a user (i.e. the HMI style) with an interactive information processing system (Rüdiger Heimgärtner, 2013b). HMI dimensions and those of their values useful for HMI design are operationalized by means of interaction indicators representing HMI metrics. Cultural interaction indicators represent the correlations between the user's interaction behavior and his culture as well as the correlation of HMI dimensions such as information speed (speed of dissemination and frequency of occurrence of information), information density (number and distance of information units) or information order (sequence of occurrence and arrangement of information) with culturally different basic patterns of behavior (Rüdiger Heimgärtner, 2012). HMI dimensions consistently represented based on cultural variables can be called "(Inter-)Cultural HMI Dimensions", which express the culturally influenced HMI style of the user in the respective cultural context, i.e. how the user interacts with the system. Using the method of the culture-oriented HMI design (MCD, see (Röse, 2002)), cultural differences are identified based on cultural dimensions and cultural variables are derived for the project. With this knowledge of cultural differences and affected aspects of the HMI system, further effects on the HMI design have been determined and supported by hypothesis-driven data transmission using user interface characteristics (see (Marcus, 2006)) and HMI dimensions (see (Rüdiger Heimgärtner, 2012)) and thereby to obtain recommendations for intercultural UI/UX design and for intercultural usability engineering (e.g. via cultural interaction indicators and a corresponding model of culture-dependent HMI (cf. (Rüdiger Heimgärtner, 2013b)).

The IUID method-mix integrates the concepts above to derive design recommendation for the designated cultural context before doing any empirical studies from scratch in order to estimate the labor expenditure in advance. The procedure of applying the IUID method-mix is as follows:

First, the application, main uses cases and the desired target cultures are chosen. Depending on the use case, the respective UI elements (e.g. layout, buttons, text fields) have to be determined and mapped to the category of the cultural variables (direct, indirect, visible, hidden) as well as to the user interface characteristics (presentation, interaction, navigation, mental model and metaphor). Using this information, the time and space related HMI dimensions concerned must be analyzed (such as information density or interaction frequency). Via the rules and the variables in the explanatory model for culturally influenced HMI, the detected HMI dimensions can be related to the cultural dimensions in order to obtain the related cultural interaction indicators. Design recommendations for intercultural user interfaces can be drawn as well (cf. (Rüdiger Heimgärtner, 2012)). For example, the higher the density of an information network (e.g. as in China compared to Germany according to (Hall \& Hall, 2009)), the stronger the values of the HMI dimensions (such as information density and interaction frequency according to (Rüdiger Heimgärtner, 2013b)), cf. Figure 1. 


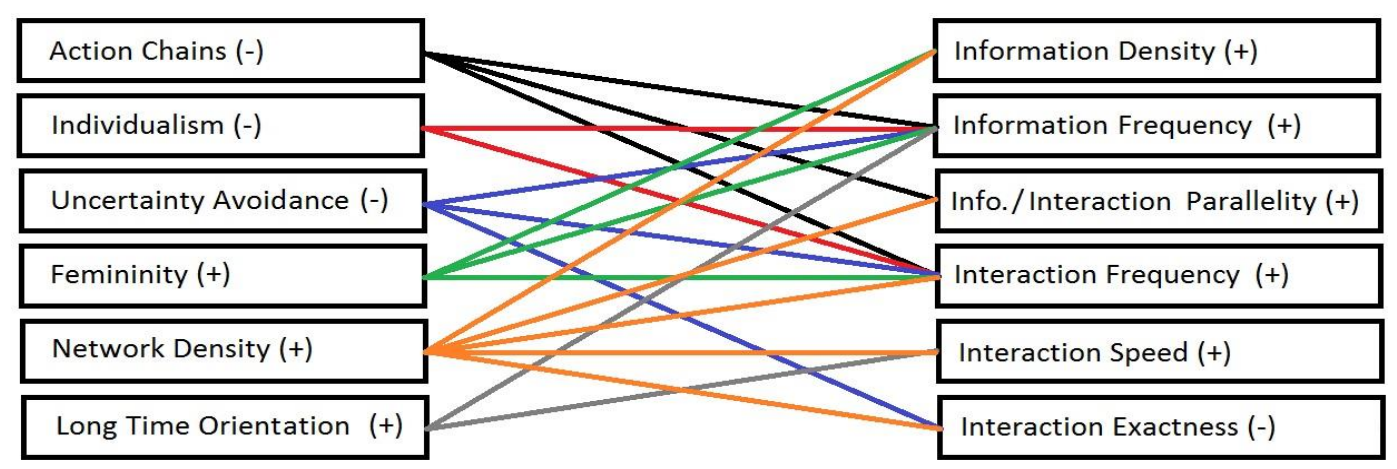

Figure 1. Model of the hypothetical relationship between cultural dimensions and HMI dimensions according to (Rüdiger Heimgärtner, 2013b)

\section{APPLICATION OF THE IUID METHOD-MIX}

Table 1 shows the results obtained by the application of this systematic procedure using the IUID method mix for some examples of applications representing the characteristics of decisive variables for the development of intercultural user interfaces.

Table 1. Application of the IUID method mix (extract of the results from IUID method mix workshops by the author)

\begin{tabular}{|c|c|c|c|c|c|c|}
\hline $\begin{array}{l}\text { Application / } \\
\text { Use Case }\end{array}$ & $\begin{array}{l}\text { Cultural } \\
\text { aspect / } \\
\text { Cultural } \\
\text { dimension }\end{array}$ & $\begin{array}{l}\text { UI } \\
\text { Character- } \\
\text { istics }\end{array}$ & $\begin{array}{l}\text { Cultural } \\
\text { variable }\end{array}$ & $\begin{array}{l}\text { HMI } \\
\text { dimension }\end{array}$ & $\begin{array}{l}\text { Cultural } \\
\text { interaction } \\
\text { indicator }\end{array}$ & $\begin{array}{l}\text { IUID } \\
\text { implication }\end{array}$ \\
\hline $\begin{array}{l}\text { Word processing } \\
\text { / Filling in a form }\end{array}$ & $\begin{array}{l}\text { Language / } \\
\text { Communicat- } \\
\text { ion network } \\
\text { density }\end{array}$ & $\begin{array}{l}\text { Presentation } \\
\text {, Interaction }\end{array}$ & $\begin{array}{l}\text { Direct } \\
\text { (word } \\
\text { length), } \\
\text { layout }\end{array}$ & $\begin{array}{l}\text { Information } \\
\text { density, } \\
\text { Interaction } \\
\text { frequency }\end{array}$ & $\begin{array}{l}\text { Average } \\
\text { number of } \\
\text { chars per } \\
\text { word, page }\end{array}$ & $\begin{array}{l}\text { Resizing, } \\
\text { calculate size } \\
\text { of display } \\
\text { according to } \\
\text { language }\end{array}$ \\
\hline $\begin{array}{l}\text { E-learning } \\
\text { system / Learning } \\
\text { content }\end{array}$ & $\begin{array}{l}\text { Communicat- } \\
\text { ion speed, } \\
\text { power } \\
\text { distance, } \\
\text { uncertainty } \\
\text { avoidance }\end{array}$ & $\begin{array}{l}\text { Presentation } \\
\text {, Navigation }\end{array}$ & $\begin{array}{l}\text { Visible } \\
\text { (character } \\
\text { set, } \\
\text { buttons) }\end{array}$ & $\begin{array}{l}\text { Information } \\
\text { presentation } \\
\text { speed }\end{array}$ & $\begin{array}{l}\text { Dialogues per } \\
\text { minute, } \\
\text { Number of } \\
\text { breaks in } \\
\text { interaction }\end{array}$ & $\begin{array}{l}\text { Adapt speed } \\
\text { of guided } \\
\text { dialogues } \\
\text { (wizards) and } \\
\text { button size }\end{array}$ \\
\hline $\begin{array}{l}\text { Phone / Looking } \\
\text { up, dialing via } \\
\text { name or number }\end{array}$ & $\begin{array}{l}\text { Communica- } \\
\text { tion speed, } \\
\text { density of the } \\
\text { information } \\
\text { network }\end{array}$ & $\begin{array}{l}\text { Interaction, } \\
\text { Mental } \\
\text { model }\end{array}$ & $\begin{array}{l}\text { Indirect } \\
\text { (online } \\
\text { operating } \\
\text { manual) }\end{array}$ & $\begin{array}{l}\text { Interaction } \\
\text { speed and } \\
\text { interaction style }\end{array}$ & $\begin{array}{l}\text { Number of } \\
\text { pressing } \\
\text { buttons per } \\
\text { task }\end{array}$ & $\begin{array}{l}\text { Choose } \\
\text { appropriate } \\
\text { input method } \\
\text { editor (IME) } \\
\text { and sorting } \\
\text { algorithms } \\
\end{array}$ \\
\hline $\begin{array}{l}\text { Word processor } \\
\text { on a mobile } \\
\text { phone / Sending a } \\
\text { short text } \\
\text { message via SMS }\end{array}$ & $\begin{array}{l}\text { Power } \\
\text { distance, } \\
\text { individualism, } \\
\text { uncertainty } \\
\text { avoidance }\end{array}$ & $\begin{array}{l}\text { Presentation } \\
\text { : text, } \\
\text { character, } \\
\text { character } \\
\text { set, layout, } \\
\text { skin, edit } \\
\text { field, send } \\
\text { button, } \\
\text { receiver list } \\
\text { box }\end{array}$ & $\begin{array}{l}\text { Direct, } \\
\text { visible, } \\
\text { surface } \\
\text { (color, } \\
\text { skin, } \\
\text { language) }\end{array}$ & $\begin{array}{l}\text { Information } \\
\text { density, } \\
\text { interaction } \\
\text { frequency and } \\
\text { speed, } \\
\text { Information } \\
\text { and interaction } \\
\text { parallelism, } \\
\text { interaction } \\
\text { exactness }\end{array}$ & $\begin{array}{l}\text { Number of } \\
\text { pieces of } \\
\text { information } \\
\text { per space, } \\
\text { Number of } \\
\text { SMS per day, } \\
\text { Number of } \\
\text { saved } \\
\text { contacts }\end{array}$ & $\begin{array}{l}\text { Adapt system } \\
\text { memory / } \\
\text { Choose } \\
\text { appropriate } \\
\text { input method } \\
\text { editor (IME) } \\
\text { and sorting } \\
\text { algorithms / } \\
\text { allow } \\
\text { customization } \\
\text { of the number } \\
\text { of entries in } \\
\text { lists }\end{array}$ \\
\hline
\end{tabular}


Assume, an UI designer wants to identify design recommendation for IUID for users from China or Germany regarding an application with the use case "sending a short text message via SMS on a mobile phone" (cf. last example in Table 1)!

The first step is to identify the cultural dimensions representing the highest cultural distance between the target cultures. The values of the cultural dimensions can be looked up in literature of cultural research (as absolute numeric values from (Hofstede et al., 2010) (cf. retrieved from https://www.hofstedeinsights.com/product/compare-countries/, last access 5|4|2019) or (Schwartz, 2004) or as relative categorial numbers by other authors of cultural dimensions such as (Hall \& Hall, 2009)).

The relationship between cultural dimensions and HCI dimensions comes into play by following the rules of the explanatory model expressing the connection between the values of the cultural dimensions and the values of the HCIDs (Rüdiger Heimgärtner, 2013b). IDV is related to information and interaction frequency. UAI is related to information and interaction frequency as well as to interaction exactness (cf. Figure 1). Hence, information frequency and interaction frequency tend to be high (e.g. for China in contrast to Germany), when individualism in a culture is low (e.g. for China (IDV=20) in contrast to Germany (IDV=67) (cf. (Hofstede et al., 2010) and (Rüdiger Heimgärtner, 2013b), cf. also Figure 1).

The next step is to identify the UI elements (e.g. text, characters, character set, layout) that are involved by the use case and to relate them to the user interface characteristics (e.g. presentation - concerning direct, visible cultural variables on the surface of the user interface (such as language, color, layout)). For example, information density is affected by the cultural presentation requirements (cf. culturally different communication patterns, (Lewis, 2006)). This different communication behavior can be expressed using adequate cultural interaction indicators such as the number of pieces of information per space, the number of SMS sent per day or the number of contacts, which in turn leads to the subsequent requirements for system design and recommendations for IUID: The HCI system needs to have enough memory for storing contacts and sent short messages.

Furthermore, it needs an input method editor for the different character sets in China and Germany in order to quickly choose and select the desired receiver name from an adequately sorted list. Hence, the user interface should be customizable to the number of presented pieces of information, e.g., the number of entries in lists or menus (cf. hierarchical versus flat menu structure, (Gould, Marcus, \& Chavan, 2006)).

These anticipated results allow the project manager to plan the most important work packages and do the related time and cost estimations for future intercultural user interfaces projects in advance.

\section{DISCUSSION}

The perception and consideration of the customs and requirements of other cultures by the developers of intercultural user interfaces is one of the main tasks within intercultural user interface design. The localization of hidden intercultural variables is very difficult to realize because the contextual relation to the cultural background as well as to the product is very strong for interaction and dialogue design. However, precisely this culturally distinct context and consequently its cultural dependency is why these patterns and non-visible intercultural variables are so important for information architecture as well as for interaction design and, hence, for the resulting dialogues (cf. (Röse, 2002), p. 98).

Although cultures are constantly changing, for a product life cycle of a few years at least trends can be determined, and for special cases of application even selective parameters can be determined which serve the intercultural user interface design. There must be at least one potential indicator as a measurement variable in order to be able to represent the character of an HMI dimension. For real use, however, several empirically proven indicators should be used.

Successful explanatory models can be applied to new examples, use cases or products and thus empirically verified, which in turn allows predictive design recommendations. The investigation and consideration of hidden cultural variables for intercultural HMI design is still ongoing. This is particularly the case in relation to the lack of research, which relates to culturally shaped interaction and dialogue design and is based on empirical research.

Nevertheless, applying the IUID method-mix is a reasonable approach towards an explanatory model for culturally influenced HMI, where areas such as intercultural usability engineering and intercultural user interface design (IUID) can benefit to the extent that the model (cf. Fig. 1) is further developed and validated. 


\section{CONCLUSION AND OUTLOOK}

Applying the IUID method-mix allows the derivation of predictive and anticipatory UI design recommendations for systems in cultural contexts in advance. Even if the IUID method-mix is at its beginning and it still must be improved upon in terms of the separability of variables and the validity of the resulting design recommendations, it represents a reasonable hybrid approach integrating several concepts to reach recommendations for intercultural user interface design. It is planned to repeat the study described in (Rüdiger Heimgärtner, 2012) to check the persistency of the relationship between cultural and HMI dimensions and therefore, the reliability of the presented model, as well as to implement an application providing the IUID method-mix for practitioners.

\section{REFERENCES}

Badre, A., \& Barber, W. (1998). Culturabilty: The Merging of Culture and Usabilty. In Proceedings of the 4th Conference on Human Factors and the Web. NJ, USA: Basking Ridge.

Castro Salgado, L., Leitão, C., \& Souza, C. (2013). Semiotic Engineering and Culture. In A Journey Through Cultures (pp. 19-42): Springer London.

Gould, E. W., Marcus, A., \& Chavan, A. L. (2006). International usability evaluation SIG: issues and strategies. Paper presented at the CHI '06 Extended Abstracts on Human Factors in Computing Systems, Montr\&\#233;al, Qu\&\#233;bec, Canada. http://delivery.acm.org/10.1145/1130000/1125537/p399 gould.pdf?ip=93.209.99.96\&acc $=$ ACTIVE\%20SERVICE \&CFID $=205638749 \&$ CFTOKEN=35037099\& $\mathrm{acm}=1$ 353416358_b94cfdac326fc273d6cec6d251f95cb8

Hall, E. T., \& Hall, M. R. (2009). Understanding cultural differences : Germans, French and Americans. Boston, Mass. u. a.: Intercultural Press.

Heimgärtner, R. (2012). Cultural Differences in Human-Computer Interaction (Paperback B: Einband - flex.(Paperback) ed. Vol. 1): Oldenbourg Verlag.

Heimgärtner, R. (2013a). Intercultural User Interface Design. In K. Blashki \& P. Isaias (Eds.), Emerging Research and Trends in Interactivity and the Human-Computer Interface.

Heimgärtner, R. (2013b). Reflections on a Model of Culturally Influenced Human-Computer Interaction to Cover Cultural Contexts in HCI Design. International Journal of Human-Computer Interaction, 29(4), 205-219. Retrieved from http://dx.doi.org/10.1080/10447318.2013.765761. doi:10.1080/10447318.2013.765761

Heimgärtner, R. (2017). Using Converging Strategies to Reduce Divergence in Intercultural User Interface Design (Vol. 05)

Hofstede, G. H., Hofstede, G. J., \& Minkov, M. (2010). Cultures and organizations : software of the mind (3. ed.). Maidenhead: McGraw-Hill.

Honold, P. (2000). Intercultural Usability Engineering: Barriers and Challenges from a German point of view. In D. Day, E. d. Galdo, \& G. V. Prabhu (Eds.), Designing for Global Markets 2. Second International Workshop on Internationalisation of Products and Systems (pp. 137-147).

Lewis, R. D. (2006). When Cultures Collide: Leading Across Cultures (Vol. 3rd Ed.): Boston/MA: Brealey.

Marcus, A. (2006). Cross-Cultural User-Experience Design. In D. Barker-Plummer, R. Cox, \& N. Swoboda (Eds.), Diagrammatic Representation and Inference (Vol. 4045, pp. 16-24): Springer Berlin Heidelberg.

Pereira, R., Baranauskas, M., \& Liu, K. (2015). The value of values for HCI: an informed discussion beyond philosophy. Paper presented at the Proceedings of the 14th Brazilian Symposium on Human Factors in Computing Systems, Salvador, Brazil.

Röse, K. (2002). Model of Culture and Their Applicability for Designing User Interfaces. Paper presented at the Paper presented at the Conference WWDU 2002- World Wide Work, Berchtesgaden.

Schwartz, S. H. (2004). Mapping and interpreting cultural differences around the world. In H. Vinken, J. Soeters, \& P. Ester (Eds.), Comparing cultures, Dimensions of culture in a comparative perspective (pp. 43-73). Leiden, The Netherlands: Brill.

Shen, S.-T., Woolley, M., \& Prior, S. (2006). Towards culture-centred design. Interact. Comput., 18(4), 820-852. doi:10.1016/j.intcom.2005.11.014

Thomas, A., Kinast, E.-U., \& Schroll-Machl, S. (2010). Handbook of intercultural communication and cooperation. Basics and areas of application. Göttingen: Vandenhoeck \& Ruprecht.

Vöhringer-Kuhnt, T. (2002). The Influence of Culture on Usability. (M.A. master thesis), Freie Universität Berlin,

Zheng, Y.-L., Rau, P.-L. P., Yueh, H.-P., Chen, P.-H., \& Huang, D.-L. (2018). An Exploratory Study on Design and Implement an Emotional Karaoke Robot (EKR), Cham. 